\title{
Análise de dados SRTM e imagens CBERS 2b na identificacãa de áreas susceptíveis à ocupação irregular em faixa de servidão de linha de transmissão de energia elétrica
}

\author{
Analysis of SRTM data and CBERS 2B images to identify areas susceptible to illegal \\ use in the easement areas power line
}

\author{
Claudionor Ribeiro Silva ${ }^{1}$, Admilson da Penha Pacheco ${ }^{2}$, Silas Valente ${ }^{3}$ \\ ${ }^{1}$ Universidade Federal de Uberlândia, MG, Brasil \\ 2,3 Universidade Federal do Pernambuco, PE, Brasil
}

\begin{abstract}
Resumo
O uso irregular de áreas destinadas às faixas de servidão de linhas de transmissão de energia elétrica (LT) tem sido recorrente em todo o território brasileiro. Quaisquer ocupações das faixas de servidão e de segurança, que não estejam contempladas no projeto de instalação da LT, são consideradas de ocupação ou uso irregular ou invasão. Este trabalho tem como objetivo estabelecer uma metodologia para identificação de áreas, dentro dessa faixa, que são suscetíveis à ocupação irregular. Foram usados dados SRTM e imagens do CBERS 2B para geração de mapas de declividade e temático, respectivamente. A área teste pertence à operadora CHESF, referente à linha de transmissão de energia elétrica de Ibicoara/Brumado, no estado da Bahia. O método proposto envolve um modelo logarítmico para classes temáticas e para declividade do terreno. Os resultados apontaram áreas da faixa de servidão que, realmente, apresentam potencial para possível ocupação.
\end{abstract}

Palavras-chave: Linha de Transmissão, Faixa de Servidão, SRTM, CBERS 2B.

\begin{abstract}
Irregular use of the easements areas power lines has been recurring throughout Brazil. Any uses of easements that are not included in the project to build the power line are considered illegal occupation or invasion. This paper aims to establish a methodology to identify areas within the easement that are susceptible to illegal occupation. SRTM data and CBERS $2 B$ image were used to generate maps of slope and thematic, respectively. The test area belongs to utility company (CHESF) and refers to the power line Ibicoara/Brumado, in the state of Bahia/Brazil. The proposed method involves a logarithmic model for thematic classes and the slope map. The results showed the easement areas that actually have potential for possible occupation.
\end{abstract}

Keywords: Power Line, Easement, SRTM, CBERS 2B. 


\section{Introdução}

Atualmente, a rede de transmissão de energia elétrica, no Brasil, ultrapassa 107 mil quilômetros de extensão. É uma distância equivalente a mais de duas vezes e meia à circunferência da Terra sobre o equador. Uma explicação para a grande extensão é a dimensão continental do País e as localizações descentralizadas das maiores e mais importantes usinas hidrelétricas (BRASIL, 2013).

Depois de deixar a usina, independentemente do tipo da fonte geradora, a energia elétrica trafega em tensões que variam de 13,8 mil volts a 750 mil volts, por meio de um sistema composto por fios e torres/postes, entre as subestações. Nesse percurso, as empresas operadoras adquirem e são responsáveis pelas faixas de terras que margeiam essas linhas de transmissão de energia elétrica (ou simplesmente linhas de transmissão - LT), denominadas de faixas de servidão e de segurança (CUCCO et al., 2013; CPFL, 2013).

A largura da faixa de servidão e segurança é determinada em função das características elétricas e mecânicas da LT. Sua função é garantir a operação, inspeção e manutenção da LT, bem como a segurança das instalações e de terceiros. Essa medida é estipulada no documento de cessão de passagem, devendo ser consultada sempre que houver uma suspeita de invasão ou solicitação de permissão para ocupação da faixa da LT. Existem casos particulares em que há a necessidade de faixa adicional, devido à presença de obstáculos como plantações de elevado porte e/ou edificações. Nesses casos, a largura da faixa deve abranger tais obstáculos (KERSTING e CENTENO, 2007; CPFL, 2013; KERSTING et al., 2013)

Devido a fatores tais como topografia, tipo de solos e condições de umidade, as faixas de servidão são comumente ocupadas indevidamente, sem prévia consulta ou autorização da empresa responsável, colocando vidas em risco. Obras, benfeitorias ou instalações, que sobrepuserem às faixas de servidão e de segurança da LT, poderão ser permitidas desde que respeitem os critérios de manutenção e operação dessa linha. Nessa área não são permitidas benfeitorias ou atividades que propiciem a permanência ou aglomeração constante ou eventual de pessoas ou aquelas que coloquem em risco a operação da LT. Estas benfeitorias ou atividades são, dentre outras: instalações e/ou construções residenciais, comerciais, industriais e/ou agropastoris de qualquer natureza, tais como residências/igrejas, estacionamentos, olarias, bares e currais; ou, ainda, áreas para a prática de esporte e/ou lazer, tais como praças, campo de futebol e pesque-pagues (CUCCO et al., 2013; CPFL, 2013).

Quaisquer ocupações das faixas de servidão e de segurança, que não estejam contempladas no projeto de instalação da LT, são consideradas de ocupação ou uso irregular ou invasão. De acordo com CPFL (2013), na ocorrência desses casos, é comum que o setor responsável pelos serviços da transmissão da LT levante dados referentes ao evento, tais como: data da inspeção que constatou a ocupação ou uso irregular ou invasão; informações das estruturas adjacentes; localização da invasão em relação à faixa de servidão e de segurança; relatório fotográfico do local e dos contatos feitos com o responsável pela invasão; situação e característica principal da irregularidade ou invasão; e riscos e perigos potenciais.

Esse levantamento de dados, somado ao cadastro das benfeitorias do uso e ocupação do solo, e à posição dos cabos condutores para controle/atualização de sua situação real, são geralmente morosos e onerosos. O conhecimento da situação real de uma LT possibilita a utilização da mesma com segurança, explorando legalmente sua capacidade. Esse conhecimento pode ser obtido por meio de informações planialtimétricas mapeadas na área. Uma tecnologia recente e relativamente barata, que pode contornar essa situação, é o sensoriamento remoto.

Atualmente existem dados de sensoriamento remoto de baixa, alta e altíssima resolução espacial e espectral, dados de radar, dados interferométricos e dados laser scanner, que permitem a representação do relevo em variadas escalas além de servirem de apoio na execução de levantamentos topográficos/geodésicos. Esses dados têm criado grande expectativa, devido à possibilidade de contornarem alguns problemas dos métodos convencionais, tais como alta densidade de vegetação, obstáculos naturais e artificiais existentes na área, licença ambiental específica e autorização de entrada na propriedade para realização do levantamento (KERSTING e CENTENO, 2007).

Em uma empresa de geração de energia, a perspectiva é de que esses dados possam fornecer subsídio para um estudo detalhado de traçados alternativos de LT, para estudo de novas potencialidades, monitoramento e conservação de LT existentes, bem como a geração de produtos indispensáveis em projetos básicos e executivos dessas linhas. Neste contexto, fomentam-se pesquisas que envolvam dados de sensoriamento remoto, que integrem dados altimétricos (laser e/ou radar) e planimétricos (imagens), visando subsidiar estudos de manutenção, operação, mapeamento e de projetos básicos e executivos de LT, atendendo aos anseios do setor elétrico (KERSTING et al., 2013).

O estudo do uso e ocupação da superfície terrestre é uma tarefa complexa devido às grandes variações que ocorrem de forma natural e antrópica. Com o surgimento de dados de alta resolução espacial, esse tipo de estudo demandou o uso de abordagens multiescalas nos processos de classificação. A classificação orientada a objetos é uma dessas técnicas que faz uso do contexto real, por meio de parâmetros como a textura e forma dos objetos (BLASCHKE e HAY, 2013).

Neste contexto, este trabalho tem como objetivo estabelecer uma metodologia para identificação de áreas, dentro dessa faixa, que são suscetíveis à ocupação irregular. 


\section{Materiais e Métodos}

No presente estudo, é proposto um método para investigação das áreas, da faixa de servidão e de segurança de LT, susceptíveis à ocupação irregular, usando classificação orientada a objetos, com imagem CBERS 2b (China-Brazil Earth Resources Satellite), e MDS (Modelo Digital de Superfície) gerado a partir de dados SRTM (Shuttle Radar Topography Mission). A Linha de Transmissão Ibicoara-Brumado, de 230 kv, escolhida para esse projeto, pertence à CHESF (Companhia Hidroelétrica do São Francisco).

\section{1 Área de Estudo e Dados Usados}

A LT usada nesse estudo está localizada no Brasil, no estado da Bahia, entre os municípios de Ibicoara e Brumado. Os principais usos e ocupações do solo, ao longo dessa LT, são Capoeiras, APP (Área de Preservação Permanente), Vegetação, Mata ciliar, Pastagens e as Sub-estações de energia da companhia CHESF.

A área teste foi escolhida estrategicamente, em cinco recortes distintos (a, b, c, d, e), compostos por coberturas variadas, como mostra a Figura 1. (a)

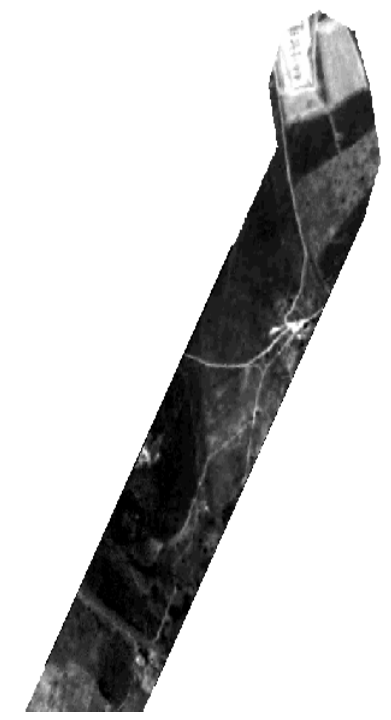

(b)

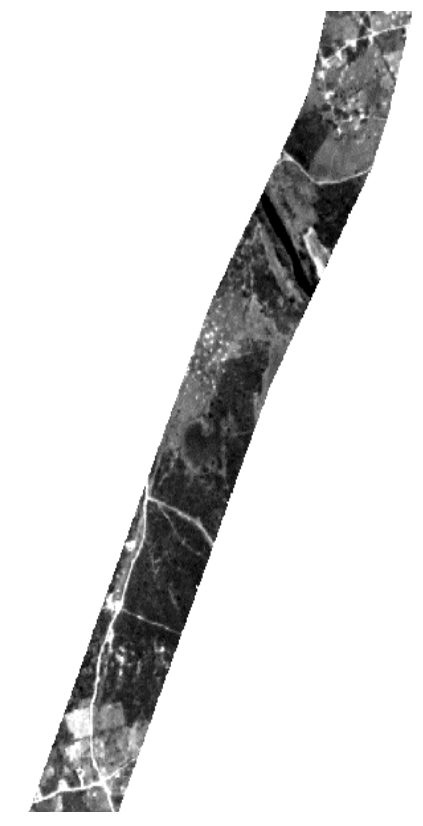

(c)

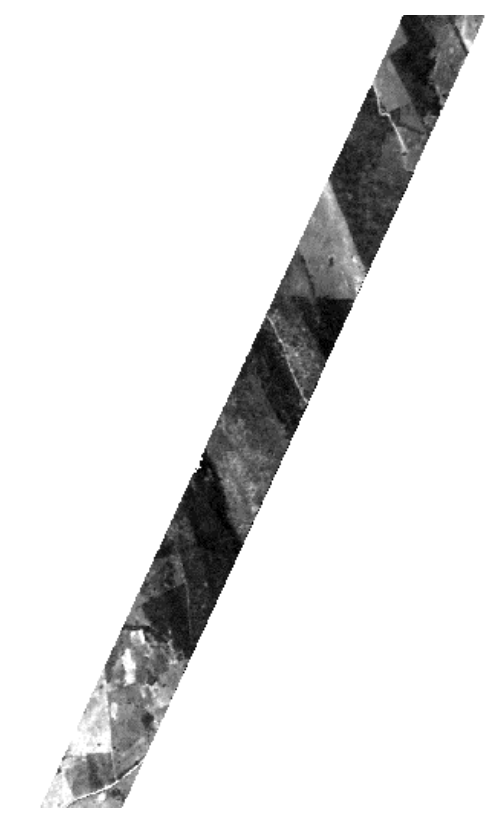

(d)

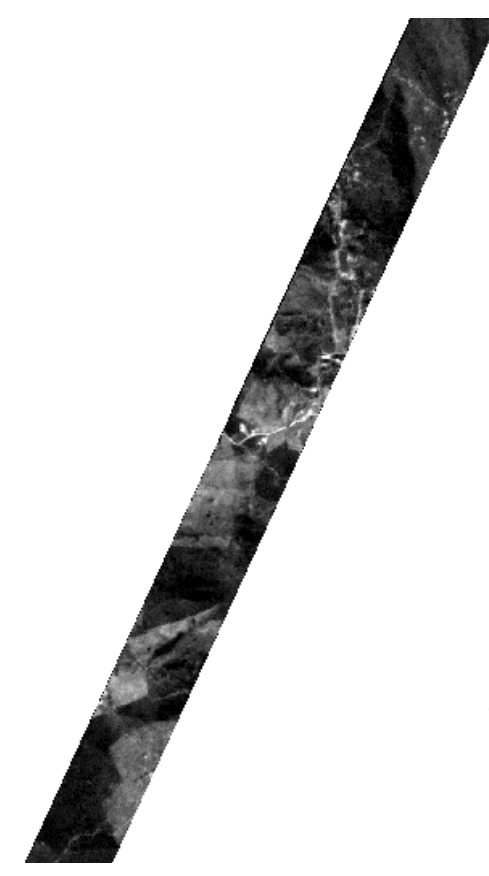

(e)

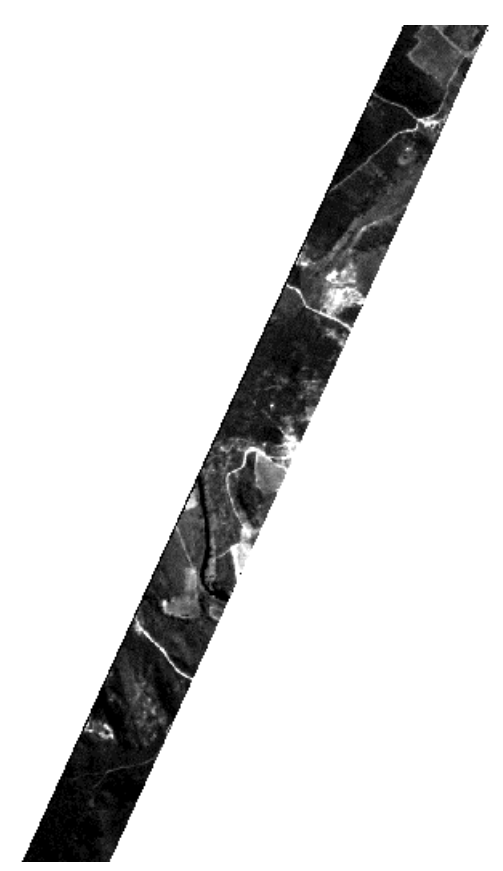

Figura 1 - Linha de transmissão Ibicoara/BA - Brumado/BA. 
Na Figura 1a destaca-se a presença de estradas e da subestação de Ibicoara, no extremo norte; essa área é delimitada pelas seguintes coordenadas UTM (Fuso 24S, Datum WGS84): 8511384,452 - 8512849,452; 242140,162 - 243207,662. Além de estradas na região sul, a Figura $1 \mathrm{~b}$ apresenta um rio mais ao norte; essa área é delimitada pelas seguintes coordenadas UTM (Fuso 24S, Datum WGS84): 8461379,452 - 8463546,952; 228177,662 $-229555,162$. A Figura 1c ilustra variadas feições, contendo faixas de cultivo, pastagens, vegetação, bem como áreas de solo exposto; essa área é delimitada pelas seguintes coordenadas UTM (Fuso 24S, Datum WGS84): 8466369,750 - 8469372,250; 230467,656 - 232205,156. Além de distintas coberturas, a área ilustrada na Figura 1d apresenta altas declividades; essa área é delimitada pelas seguintes coordenadas UTM (Fuso 24S, Datum WGS84): 8470179,750 - 8473167,250; 232227,656 - 233940,156. A Figura 1e apresenta área sombreada no extremo sul, um rio na parte central e estradas na região norte; essa área é delimitada pelas seguintes coordenadas UTM (Fuso 24S, Datum WGS84): 8480554,750 - 8483552,250; 236972,656-238710,156.

As cenas ilustradas na Figura 1 são imagens pancromáticas (Figura 1) do sensor HRC (Panchromatic Camera of High Resolution), do satélite CBERS 2B, obtidas no dia 11 de agosto de 2009, na órbita 151 (INPE, 2013). A câmera HRC foi elaborada para coletar informações (imagens) com resolução espacial de 2,7 metros e resolução espectral de 0,5 a $0,8 \mu \mathrm{m}$.

Foi usado, também, um conjunto dos dados SRTM, distribuídos gratuitamente pela NASA (National Aeronautics and Space Administration), com 3 segundos de arco (90 metros) de resolução espacial (DLR, 2013). Os dados SRTM permitem a geração de MDS, que é fonte de informação para a obtenção do mapa de declividade (RABUS et al., 2003). Embora não apresente nenhuma melhoria na qualidade, os dados SRTM foram reamostrados para um grid de 2,7 metros, para compatibilizar com as imagens CBERS 2B, apresentadas acima. Os valores de elevação SRTM são codificados em metros, correspondendo á altura elipsoidal para o Datum WGS84.

$\mathrm{O}$ arquivo com o posicionamento das Torres foi cedido pela Chesf, obtido a partir de um levantamento topográfico.

\section{Método}

O método proposto é dividido em duas etapas: processo de Segmentação/Classificação e modelo para identificação de áreas aptas à ocupação.

\subsection{Segmentação e Classificação das Imagens}

A segmentação foi realizada usando o método de classificação orientada a objetos, implementado no módulo EX do software ENVI 4.8. Nesse processo de segmentação foram escolhidos, empiricamente, o valor de escala igual a 90, a fusão igual a 95 e a alternativa de segmentação sem refinamento, em um processo interativo no ENVI 4.8. As classes usadas foram: vegetação, cultivo/ pastagem, estradas, solo exposto, construções e rios.

\subsection{Modelo Proposto}

O método proposto busca modelar parâmetros que influenciam, diretamente, no processo de identificação de áreas de faixa de servidão de LT, susceptíveis à ocupação irregular. Os modelos levam em consideração os seguintes parâmetros: Declividade do terreno $(P d)$, Distância das torres $(P t)$, Área construída/edificada $(P c)$, Solo exposto $(P s e)$, Estradas/rodovias $(P e)$, Vegetação $(P v)$, Cultivo/Pastagens $(P c p)$, Área coberta por água $(P a)$ e Sombras/Nuvens $(P s n)$. Esses parâmetros foram definidos tendo por base as classes/objetos existentes/visíveis na imagem usada e as informações de relevo (SRTM) e de posicionamento das torres da LT (arquivo Chesf).

O primeiro modelo (Equação 1) proposto é dado pela função logarítmica que pondera a influência da declividade no processo de ocupação da faixa de servidão em LT, como ilustra a Figura 2.

$$
P d=1-\log _{10}^{p}
$$

onde, $p=\frac{9}{d m a ́ x} x+1 ; x$ é o valor da declividade e $d m a ́ x$ é a declividade máxima na área analisada.

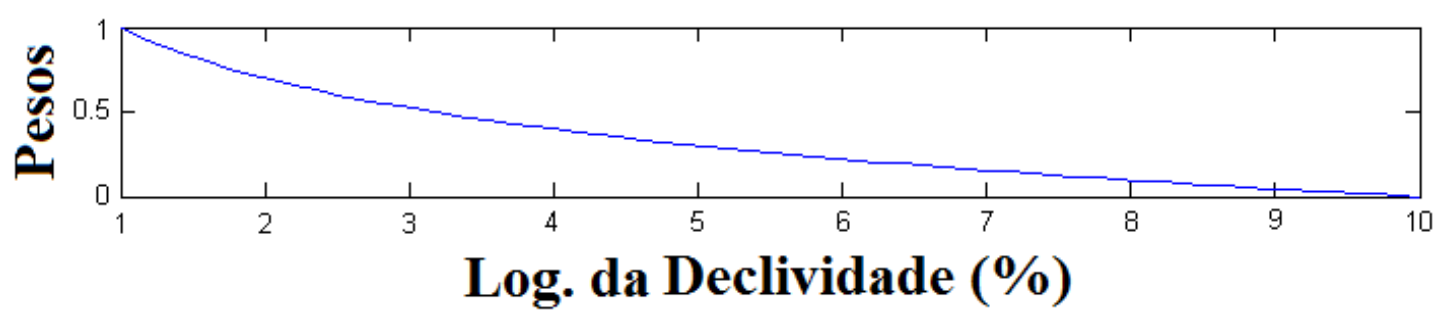

Figura 2 - Ponderação correspondente à declividade do terreno. 
Neste modelo, a premissa é de que áreas mais planas são mais propícias à invasão ou ocupação irregular.

A distância das torres é outro parâmetro importante, porque as áreas mais próximas geralmente são respeitadas, devido à estrutura física instalada. A ponderação proposta para esse parâmetro é dada pela Equação 2.

$$
\begin{array}{cc}
\text { Se } x \leq f s & P t=\log _{10}^{p} \\
\text { Senão } & P t=1
\end{array}
$$

onde, $p=\frac{9}{f s} x+1 ; x$ é a distância de afastamento (distância entre a base de uma torre e o ponto analisado) e $f s$ é a largura da faixa de servidão da LT.

Para esse parâmetro, toda área afastada de uma torre, com distância maior que a largura da faixa de segurança, é totalmente suscetível à invasão (peso igual a 1), como mostra a Figura 3.

Inversamente ao caso das torres, as áreas mais próximas às estradas/rodovias são mais susceptíveis à ocupação, pela comodidade de deslocamento para outros locais. Dessa forma, a ponderação proposta para esse parâmetro é dada pela Equação 1 (), alterando apenas o valor de ; onde é a distância de afastamento das estradas/ rodovias e é a mesma largura da faixa de servidão da LT já apresentada. O gráfico terá o mesmo comportamento daquele apresentado na Figura 2.

Nesse caso, deveria ser levada em consideração a área da faixa de domínio da estrada/rodovia, contudo, devido à particularidade do Art. 50 do Código de Trânsito Brasileiro, que expõe que o uso da faixa de domínio obedecerá às condições de segurança do trânsito (CTB, 2013), insinuando que essa área também é passível de ocupação irregular, foi atribuída a mesma ponderação correspondente à faixa de servidão.

As áreas próximas aos corpos d'água são igualmente desejadas, nas ocupações irregulares, como são os locais próximos às estradas. Nesse contexto, a ponderação proposta para esse parâmetro reduz com o afastamento do leito do corpo d'água, conforme Equação 3.

$$
\begin{array}{cc}
\text { Se } x \leq \text { lr } / 2 & P a=0 \\
\text { Se } \operatorname{lr} / 2<x \leq \text { lapp } & P a=\log _{10}^{p} \\
\text { Se } x>\text { lapp } & P a=1-\log _{10}^{p 1}
\end{array}
$$

onde, $p=\frac{9}{\text { lapp }} x+1 ; p 1=\frac{9}{100 \cdot \operatorname{lapp}} x+1 ; x$ é o afastamento em relação ao rio; $l r$ é a largura do rio; e, lapp é a largura das Áreas de Preservação Permanente (APP) ,coletada de acordo com o Art. 4 do Novo Código Florestal (NCF, 2013), que trata da largura das faixas marginais (APP) de qualquer curso d'água natural. A largura (lr) de cada rio é obtida pela média de, no mínimo, cinco medidas realizadas ao longo do trecho do seu leito, que cruza a faixa de servidão.

De acordo com o gráfico da Figura 4, as áreas submersas tem peso nulo, indicando que não ocorrerá ocupação; as áreas correspondentes às APP's, embora proibidas, podem ser invadidas; e as áreas fora das APP's podem ser totalmente invadidas, mas quanto mais distante da água, menor o interesse.

Os demais parâmetros são medidos por meio de um mapa temático, onde cada tema recebe sua ponderação equivalente. Para as áreas construídas/edificadas existentes, a ponderação é $100 \%$, uma vez que já existe a ocupação $\left(P_{c}=1\right)$. A classe "Solo exposto" é ponderada

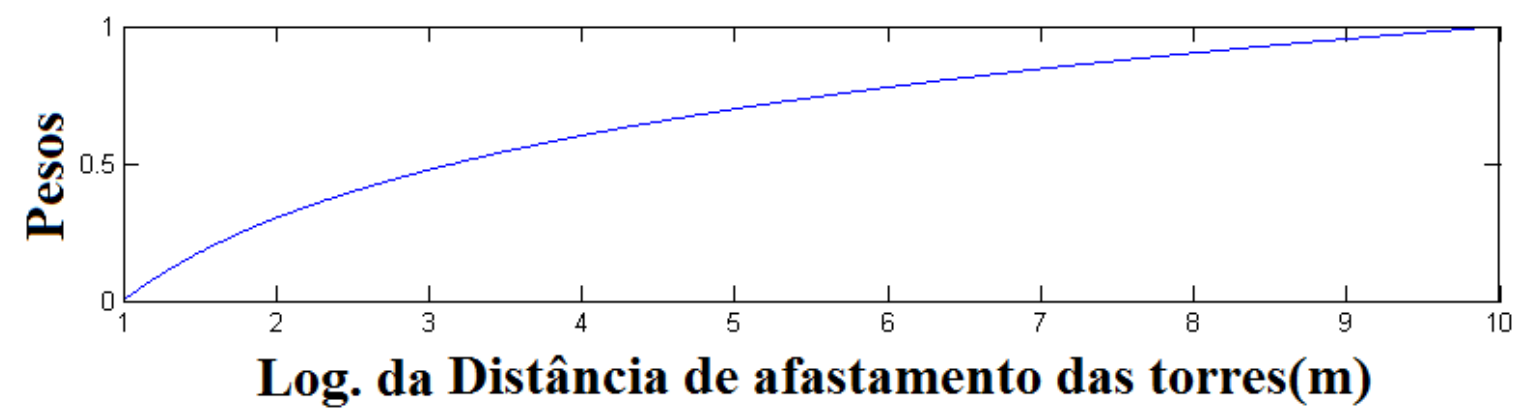

Figura 3 - Ponderação correspondente à distância das torres.

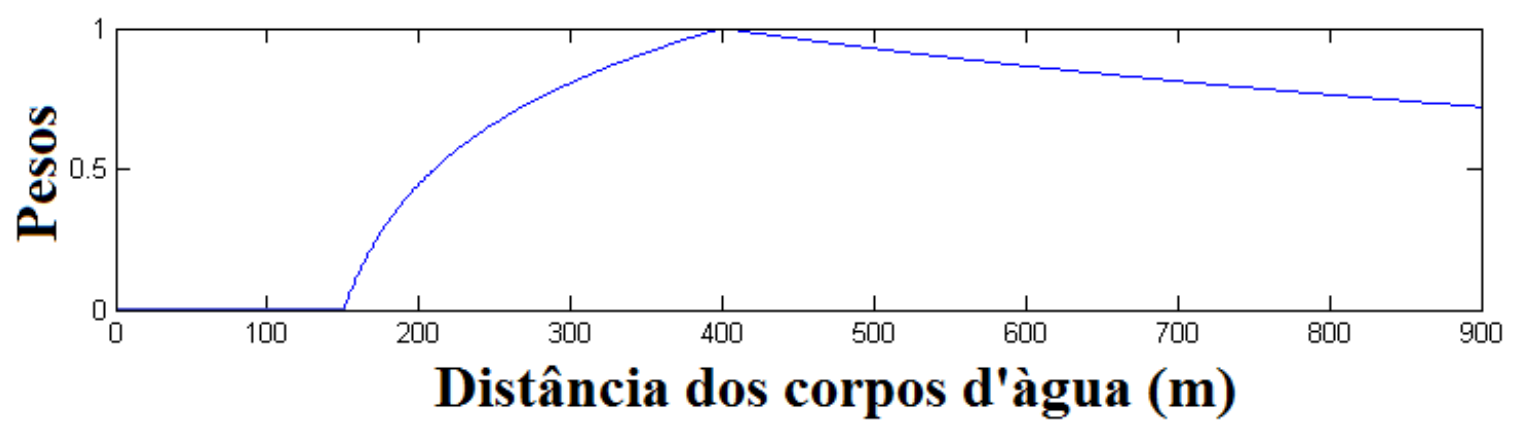

Figura 4 - Ponderação correspondente à proximidade de corpos d’água. 
considerando a influência dos parâmetros: declividade $(P d)$, distância de torres $(P t)$ e distância de estradas $(P e)$, conforme modelo proposto na Equação 4.

$$
P s e=P d \cdot P t \cdot P e
$$

A área coberta por "vegetação" $(P v)$, as classes de $p=\frac{9}{0,8 \cdot f s} x+1, p=\frac{9}{0,9 \cdot f s} x+1$ e $p=\frac{9}{0,7 \cdot f s} x+1$,

"cultivo e pastagem" (Pcp), e as áreas sobrepostas por "sombras e nuvens" (Psn) são ponderadas com base na Equação 1, alterando apenas os valores de $p$, com respectivamente. Nesses modelos propostos, a largura da faixa de servidão $\left(f_{s}\right)$ é multiplicada por uma constante que permite aumentar ou reduzir o peso dos parâmetros. A ponderação aumenta com o crescimento do valor da constante.

Finalmente, o modelo proposto para identificar Áreas Suscetíveis à Ocupação Irregular (ASOI), em faixas de servidão de LT, é dado pela Equação 5.

$$
A S O I=P d \cdot P t \cdot P c \cdot P s e \cdot P e \cdot P v \cdot P c p \cdot P a \cdot P s n
$$

Todo o tratamento das imagens foi realizado usando o software ENVI 4.8. O registro da imagem CBERS 2B, com os dados SRTM, foi realizado com RMS menor que o pixel. A reamostragem dos dados SRTM foi realizada com o interpolador "bilinear". As imagens (layers) de distâncias (das torres, dos rios, e das estradas) foram geradas com a função "Buffer". O buffer das distâncias das torres foi realizado a partir dos pontos (coordenadas) fornecidos pela Chesf. A declividade foi gerada a partir da função "Topographic -> Modeling".

O processamento com os modelos propostos foi realizado com rotinas elaboradas em ambiente Matlab2012. Essas rotinas permitiram tarefas de leituras e multiplicação dos layers (imagem de cada parâmetro) gerados a partir das imagens CBERS 2B e SRTM.

\section{Resultados e Discussões}

Os cinco recortes de imagens, juntamente com a imagem declividade, foram submetidos ao modelo proposto e as imagens geradas, apontando as áreas da faixa de servidão suscetíveis à ocupação irregular, podem ser vistas na Figura 5.

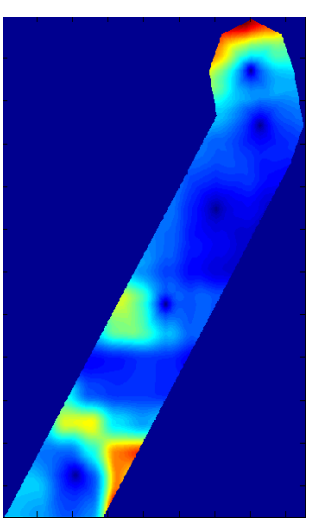

(a)

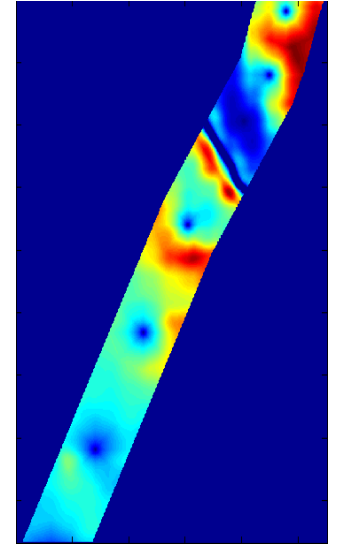

(b)

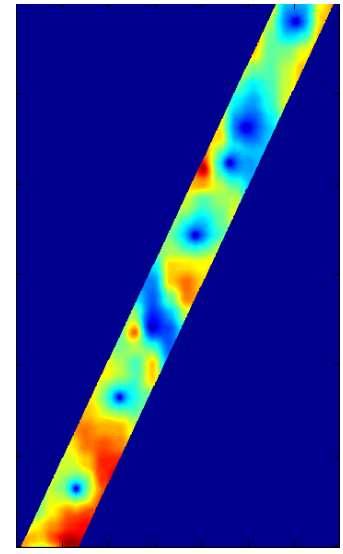

(c)

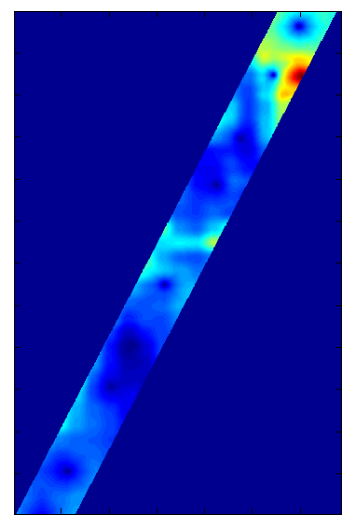

(d)

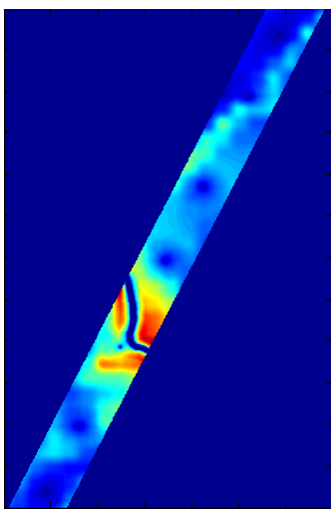

(e)

Figura 5 - Áreas de faixa de servidão suscetíveis à ocupação irregular. 
O resultado obtido com o primeiro recorte (Figura 1a) mostra que a área já ocupada pela CHESF (extremo Norte) aparece como uma região apta a ser ocupada, como ilustra a Figura 5a. Nesse caso, a área já foi ocupada para instalação da subestação da CHESF. No extremo Sul da imagem, aparece outra área mais extensa que apresenta forte aptidão para a ocupação irregular. Observando a Figura 1a, percebe-se que essa área contém uma estrada e está localizada em um ponto afastado de torres, o que instiga a ocupação e transmite confiança artificiosa ao invasor. A região central da Figura 1a apresenta uma área levemente idônea para a ocupação irregular. Embora essa área seja cercada por duas estradas, o que aumentaria sua aptidão à ocupação, apresenta duas desvantagens: a presença de vegetação e a proximidade de torres. Todo o restante da área apresenta baixa aptidão ao processo de invasão.

No segundo recorte (Figura 5b), as áreas de maiores aptidões à invasão estão no extremo Norte e região central. Em ambas as regiões predomina a classe cultivo/ pastagem, como mostra a Figura $1 b$. Somado a isto, existem trechos com solo exposto (ou desmatamento) na região, o que pode ser um atrativo à invasão, justificando os altos valores de aptidão à ocupação. Na região central, as áreas aptas estão divididas em duas faixas: uma à margem esquerda do rio, preservando o afastamento das APP's, e a outra mais ao Sul, em uma área relativamente plana. A presença de vegetação nessa região central foi fator determinante na redução da área de aptidão para ocupações, uma vez que os outros parâmetros contribuem para tal. Nota-se que as áreas próximas à margem direita do rio apresentaram baixa aptidão. Esse fato pode ser explicado pela alta declividade da encosta deste lado do rio. Na margem esquerda do rio, além do cultivo/ pastagem e proximidade da água, a baixa declividade proporcionou o destaque apresentado no vale, com forte aptidão ao processo de invasão.
Diferentemente das duas primeiras áreas teste, na terceira são visíveis as regiões de maiores aptidões distribuídas ao longo de toda a área (Figura 5c); com destaque para uma porção localizada no Sul. Um fato interessante, no resultado dessa área teste, é a baixa aptidão atribuída à região de escarpas, de altas declividades, demonstrando a impossibilidade de ocupação em áreas de alcantil.

A área 4 (Figura 5d), de forma geral, apresentou baixa propensão à ocupação, o que pode ser visto em toda a região Sul, Centro e em parte do Norte. Essa área é fortemente afetada pelas altas declividades, presença de vegetação e poucas de estradas. A pequena região apta à ocupação está localizada no Norte dessa área de estudo, sendo uma maior inclinação à ocupação na região mais ao Leste dessa porção. Além da declividade, os sombreados (nas escarpas) também influenciaram nos valores de suscetibilidade à ocupação dessa área, reduzindo sua aptidão.

Finalmente, na área de estudo ilustrada na Figura 5e, pode ser observado que as regiões de aptidão à ocupação são distribuídas por toda a área, mas com baixa intensidade, se comparada à área teste 3 . Na região Sul observa-se baixa tendência à ocupação, devido especialmente ao sobreamento existente nesse local (Figura 1e). No extremo Norte e em trechos da região central também ocorrem baixos valores de aptidões. Nesses casos, a baixa aptidão é atribuída à presença de vegetação densa nessas áreas. Em ambas as margens do rio ocorrem altos valores de aptidão. Uma explicação seria as baixas declividades somadas ao solo exposto, pastagens e estradas existentes naquela área. Observa-se que, nas proximidades da torre existente nessa região, a aptidão é fortemente reduzida, respeitando sua presença física.

A Tabela 1 mostra uma relação quantitativa das áreas aptas à invasão/ocupação irregular, em função de intervalos de valores de aptidão obtidos com o modelo proposto.

Tabela 1 - Valores das áreas de faixa de servidão suscetíveis à ocupação irregular.

\begin{tabular}{c|c|c|c|c}
\hline Áreas $\left(\mathrm{m}^{2}\right)$ & $\begin{array}{c}\text { Intervalo 1 } \\
(0.4-0.5)\end{array}$ & $\begin{array}{c}\text { Intervalo 2 } \\
(0.5-0.6)\end{array}$ & $\begin{array}{c}\text { Intervalo 3 } \\
(0.6-0.7)\end{array}$ & $\begin{array}{c}\text { Intervalo 4 } \\
(>0.7)\end{array}$ \\
\hline $\begin{array}{c}\text { Área teste } \\
1\end{array}$ & 25575,00 & 14262,50 & 4287,50 & 1256,25 \\
\hline $\begin{array}{c}\text { Área teste } \\
2\end{array}$ & 92075,00 & 49006,25 & 28737,50 & 0,00 \\
\hline $\begin{array}{c}\text { Área teste } \\
3\end{array}$ & 241950,00 & 160662,50 & 71350,00 & 11225,00 \\
\hline $\begin{array}{c}\text { Área teste } \\
4\end{array}$ & 44606,25 & 22137,50 & 9743,75 & 6081,25 \\
\hline $\begin{array}{c}\text { Área teste } \\
5\end{array}$ & 47887,50 & 36618,75 & 9668,75 & 1000,00 \\
\hline
\end{tabular}


O intervalo 1 (0.4 - 0.5) corresponde à cor amarelada, mais próxima do ciano, apresentada nas imagens da Figura 5. Os intervalos 2, 3 e 4 são representados, respectivamente, pelas cores: amarelo, vermelho e vermelho mais intenso. Pela definição do modelo proposto, quanto mais próximo de 1 mais apta será a região ao processo de invasão ou ocupação irregular. Dessa forma, o intervalo 1 é menos apto e o 4 é fortemente apto ao processo supracitado.

Exatamente $26 \%$ da área teste 3 pertence ao intervalo 1 , o que corresponde a 24,195 hectares. É um valor relativamente alto, se comparado aos $4,82 \%$ da área teste 4 (4,460 hectares), no mesmo intervalo. No intervalo 2 , a área correspondente à área teste 3 ainda é destaque, com $17,27 \%$ de sua área total. A menor área nesse intervalo também corresponde à área teste 4 . No intervalo 3, a menor área $(0,90 \%)$ propícia à invasão/ocupação irregular pertence à área teste 1, com aproximadamente 0,429 hectares. A maior área, nesse mesmo intervalo, ainda pertence à área teste $3, \operatorname{com} 7,67 \%$, e na sequência está a área teste 2 , com $4,19 \%$.

No intervalo mais crítico (intervalo 4), onde as áreas apontadas merecem atenção/vigilância especial, a área correspondente à área teste 3 ainda é superior, mas com valor mais modesto, de 1,21\% de sua área total. A área teste 2 não apresenta nenhuma área com essa ponderação de risco de invasão. Com $0,66 \%$ da sua área total, a área teste 4 está na segunda colocação de prioridade de análise. Por fim, com áreas de $0,26 \%$ e $0,11 \%$,estão, respectivamente, as áreas testes 1 e 5 .

\section{Considerações Finais}

Na ocorrência de ocupação irregular de faixas de servidão de LT, é comum que o setor responsável pelos serviços da transmissão da LT levante dados referentes ao evento, tais como: a) data da inspeção que constatou a ocupação ou uso irregular ou invasão, b) informações das estruturas adjacentes, c) localização da invasão, em relação à faixa de servidão e de segurança, d) relatório fotográfico do local e dos contatos feitos com o responsável pela invasão, e) situação e característica principal da irregularidade ou invasão, f) riscos e perigos potenciais; o que demanda tempo e muito trabalho.

As imagens CBERS 2B, em conjunto com os dados SRTM, possibilitam a geração de produtos que podem ser úteis em projetos básicos e executivos de LT. Os produtos gerados nesse estudo demonstram essa possibilidade, apontando locais suscetíveis à ocupação irregular nas faixas de servidão de LT. Tendo por base a interpretação visual das imagens CBERS 2B, é possível afirmar que os resultados obtidos são coerentes, uma vez que as áreas que apontam aptidão para serem ocupadas irregularmente condizem com a realidade local.

A grande vantagem do método, além da redução do custo do projeto, uma vez que ambos os dados (SRTM e CBERS 2B) são disponibilizados gratuitamente, o que possibilita a facilidade de atualização e geração de bancos de dados; é que os resultados possibilitam a observação/ fiscalização do quadro de ocupação da faixa de servidão em locais específicos, antecipando à ocorrência de invasões, tomando decisões para evitá-las nesses locais.

Todos os valores de área decrescem do intervalo 1 para o intervalo 4 , o que pode facilitar o trabalho de fiscalização/monitoramento da faixa de servidão, uma vez que pode ser feito por intervalos, dando prioridade ao mais urgente (intervalo 4 ).

\section{Agradecimentos}

Agradecemos a Companhia Hidroelétrica do São Francisco (CHESF) pela disponibilização dos dados topográficos da LT Ibicoara/Brumado.

\section{Referências}

BLASCHKE, T. and HAY G. J. Object-oriented Image Analysis and Scale-space: Theory and Methods for Modeling and Evaluating Multiscale Landscape Structures. Disponível em:http://homepages. ucalgary.ca/ gjhay/PDFs/White papers/2001 Blaschke Hay OO scale space.pdf. Acesso em: 26/06/2013.

BRASIL. Setor Elétrico - Linhas de transmissão. Disponível em: http://www.brasil.gov.br/ infraestrutura/2011/12/rede-de-transmissao-supera107-mil-quilometros. Acesso em: 30/06/2013.

CPFL - Companhia Paulista de Força e Luz. Ocupação de Faixa de Linha de Transmissão. Disponível em: http://www.cpfl.com.br/LinkClick.

aspx?fileticket=Fpa6H6MUvvY\%3D\&tabid=467\&mi\%20 d=1224. Acesso em: 25/04/2013.

CTB - Código de Trânsito Brasileiro (LEI № 9.503, de 23 de setembro de 1997). Disponível em: http:// www.planalto.gov.br/ccivil 03/leis/19503.htm. Acesso em: 30/06/2013.

CUCCO, J.; BOSCATTO, F.; OLIVEIRA, F. H.; SANTO, M. A. Modelo de avaliação de potencial de risco a invasão em faixas de servidão de linhas de transmissão de energia elétrica. Disponível em: http://www.geolab.faed.udesc.br/publicacoes.html. Acesso em: 15/03/2013.

DLR - Products SRTM. Disponível em: http://www2. jpl.nasa.gov/srtm/. Acesso em: 05/05/2013.

INPE - Instituto Nacional de Pesquisas Espaciais. 
Disponível em: http://www.cbers.inpe.br/. Acesso em: 05/05/2013.

KERSTING, A. P. B.; KERSTING, J.; FELSKY, C. E. F.; MÜLLER, M. Airborne LIDAR and GIS Tools in Transmission Line Re-Rating Projects. Disponível em: http://gis.tavanir.org.ir/maghalat/pap2075.pdf. Acesso em: 26/06/2013.

KERSTING, A. P.; CENTENO, J. A. S. Object Oriented Transmission Line Corridors Classification Using LiDAR Technology and a Non-Metric Digital

Camera. Boletim de Ciências Geodésicas, v.13, n.2, 2007, p.295-315.

NCF - Novo Código Florestal (LEI № 12.651, de 25 de maio de 2012). Disponível em: http://adcon.rn.gov. br/acervo/emater/doc/doc000000000001052.pdf. Acesso em: 30/06/2013.

RABUS, B.; EINEDER, M.; ROTH, A.; BAMLER, R. The shuttle radar topography mission - a new class of digital elevation models acquired by spaceborne radar. Journal Photogrammetry and Remote Sensing. n.53, 2003, p.241-262. 